\title{
NOTE ON THE DETERMINATION OF CASEIN PRECIPITATED BY RENNET.
}

By H. Droop Richmond, F.I.C.

(Read at the Meeting, February 4, 1903.)

IN the ANaLYsT (xxvii., 37) an abstract of a paper on this subject by L. Lindet appears. He objects to the usual methods of casein determination as being inexact, and proposes a densimetric method for the determination of the casein precipitated by rennet. As he mixes up the relations between density, specific volume, and percentages by weight and volume, I wish to point out that his method and formulæ are approximations only. Further, as he does not point out that what he estimates is not casein, but the curd produced by rennet, which contains roughly 10 per cent. of mineral matter, it is advisable to draw attention to the exact meaning of the figure obtained.

If we have a solution (milk) containing two substances (whey and curd), the density of one of them (whey) can be calculated, if we know the density of the solution (milk) and of the substance removed (curd) and the percentage rernoved.

Starting from the definition Density $=\frac{\text { weight }}{\text { volume }}$, and taking for convenience 100 c.c. of milk, we have-

$$
\mathrm{D}_{\mathrm{w}}=\frac{(100-c) \mathrm{D}_{\mathrm{M}}}{100-\frac{c \mathrm{D}_{\mathrm{M}}}{d}}=\frac{\text { total weight }- \text { weight of curd }}{\text { total volume }- \text { volume of curd }},
$$


where $c=$ percentage by weight of curd,

$\mathrm{D}_{\mathrm{M}}=$ density of the milk,

$\mathrm{D}_{\mathrm{w}}=$ density of the whey,

$d=$ density of the curd.

Solving the above equation for $c$, we get :

$$
c=\frac{100\left(\mathrm{D}_{\mathrm{M}}-\mathrm{D}_{\mathrm{w}}\right)}{\mathrm{D}_{\mathrm{M}}\left(1-\mathrm{KD}_{\mathrm{w}}\right)}, \text { where } \mathrm{K}=\frac{1}{d}
$$

From my own experiments I deduce the value 0.71 for $K$. This formula may be simplified to the approximation formula :

$$
c=\frac{100\left(\mathrm{D}_{\mathrm{M}}-\mathrm{D}_{\mathrm{W}}\right)}{1 \cdot 036(1-0.71 \times 1.029)} \text {, or } \frac{100\left(\mathrm{D}_{\mathrm{M}}-\mathrm{D}_{\mathrm{W}}\right)}{0 \cdot 279},
$$

which gives the factor for multiplication as 3.58 , a figure in substantial agreement with Lindet's $3 \cdot 5$.

Lindet also gives a formula for calculating the specific gravity of the milk free from fat, in order to eliminate the influence of the fat, but his formula is not correct. The true formula should be as above.

$$
\mathrm{D}_{\mathrm{S}}=\frac{(100-f) \mathrm{D}_{\mathrm{M}}}{100-\frac{f \mathrm{D}_{\mathrm{M}}}{0.93}},
$$

where $D_{\mathrm{S}}=$ density of the milk minus fat,

$\mathrm{D}_{\mathrm{M}}=$ density of the milk.

$f=$ percentage by weight of fat.

A very good and simple approximation formula is :

$$
\mathrm{D}_{\mathrm{s}}=\frac{1000 \mathrm{D}_{\mathrm{M}}+f}{1000}
$$

The whey produced from milk containing fat always contains a small percentage of fat, and the density of the whey should be corrected in a manner similar to that of the milk.

A small error is introduced by using the corrected densities, because the curd removed is calculated as a percentage of the milk devoid of fat, and not of the whole milk. This can be approximately corrected by using a slightly smaller factor. The difference between Lindet's figure $(3 \cdot 5)$ and my own $(3.58)$ may be due to this.

A simple approximation formula, which will give very fair results, is :

$$
c=\left\{\mathrm{G}_{\mathrm{M}}+f_{\mathrm{M}}-\left(\mathrm{G}_{\mathrm{W}}+f_{\mathrm{W}}\right)\right\} \times 0 \cdot 35,
$$

where $c=$ percentage of curd by weight,

$\mathrm{G}_{\mathrm{M}}=$ lactometer degrees of milk,

$\mathrm{G}_{\mathrm{W}}=$ lactometer degrees of whey,

$f_{M}=$ percentage of fat in milk,

$f_{\mathrm{W}}=$ percentage of fat in whey.

The weight of cheese obtained does not depend entirely on the percentage of curd, but the fat taken down with the curd is an important factor. The curd estimated by this method will not agree with the proteid precipitated, but with proteid 
plus mineral matter, the latter being about 10 per cent. of the curd; still less will the figure obtained represent the casein in the milk.

It should be clearly understood that Lindet's method estimates only the percentage of dry curd produced by rennet, and does not give an estimation of proteid matter. With this limitation, the method should be a useful addition to our dairy tests.

\section{Discussion.}

Mr. Richmond, in reply to questions put by the President, Dr. Lewkowitsch, and Dr. Voelcker, said that this was a method for calculating the amount of curd separated from the milk by the rennet, and was capable of being used as a practical test. It would not indicate directly the amount of cheese produced in practice, because of the variations which occurred in the proportions of fat and water. It would, however, afford a rough indication of the value of milk for cheese-making. He had not compared the calculated results with the amount of cheese produced, but they were in agreement with the amount of the curd before it was made into cheese.

Mr. Lloyd thought that for the cheese-maker it was less important to know the quantity of casein than to know the quantity of curd which he ought to obtain. The use of such a method as this by anyone but a most careful chemist seemed likely to be fraught with many pitfalls. The composition of the whey would vary with the temperature and with the time for which the rennet was allowed to act. For every moment that the whey acted on the curd precipitated by the rennet there was an increase of acidity, and simultaneously with that a withdrawal of lime-salts from the curd.

Mr. RIChmond said that, whereas at present the cheese-maker worked in the dark, he could by the use of a method such as this arrive at some idea of the amount of curd he ought to obtain ; and then, assuming an average percentage of curd in the finished cheese, he could calculate approximately how much cheese he ought to expect. After all, the increase of acidity referred to by Mr. Lloyd would not, he thought, be so great as to affect very seriously the density factor; nor would any great difference be caused by the enzyme action which would be also proceeding. As the density of the actual whey obtained could be determined, any errors due to these causes would be practically eliminated.

Dr. Schidrowitz inquired whether any attempt had been made to measure the strength of the enzymic action in whey.

Mr. Richmond said that a quite well-known method of determining the strength of rennet-which was really the strength of the enzyme-was by adding a known quantity of the rennet to milk, and observing the time in which, at a constant temperature, curdling was produced. 